\title{
Uma espécie e uma combinação novas de Alchornea Sw. (Euphorbiaceae) da Bolívia 1
}

\author{
RICARDO DE S. SECCO ${ }^{2}$
}

(recebido em 08/05/98; aceito em 20/01/99)

ABSTRACT - (A new species and a new combination of Alchornea Sw. (Euphorbiaceae) from Bolívia ). A new species, Alchornea anamariae R. Secco, and a new combination, A. pubescens (Britton) R. Secco, based on Conceveiba pubescens Britton, are proposed to Bolivia. The first one has more affinity with $A$. bogotensis Pax \& K. Hoffm. and the other with A. sidifolia Muell. Arg. Descriptions, illustrations and comments on taxonomic relationships as well as geographic distribution are presented.

RESUMO - (Uma espécie e uma combinação novas de Alchornea Sw. (Euphorbiaceae) da Bolívia). Uma nova espécie, Alchornea anamariae R. Secco, e uma nova combinação, A pubescens (Britton) R. Secco, baseada em Conceveiba pubescens Britton, são propostas para a Bolívia. A primeira tem maior afinidade com A. bogotensis Pax \& K. Hoffm. e a segunda com A. sidifolia Muell. Arg. São apresentadas descrições, ilustrações, comentários sobre relações taxonômicas e distribuição geográfica dessas espécies.

Key words - Alchornea Sw., Alchorneae, Euphorbiaceae, plant taxonomy, new species, new combination

\section{Introdução}

O gênero Alchornea (Euphorbiaceae) é incluído na subfamília Acalyphoideae, tribo Alchorneae, subtribo Alchorneinae (Webster 1994) e é próximo de Aparisthmium Endl. (Secco 1997). É um táxon de distribuição pantropical, com 41 espécies encontradas na Ásia, África, Malásia, Madagascar, Antilhas, México, América Central e América do Sul (exceto no Chile e Uruguai). Das 22 espécies neotropicais de Alchornea, 16 ocorrem na Colômbia, centro de diversidade do gênero. Porém, nenhuma é endêmica. Um segundo centro de diversidade está na Bolívia, onde ocorrem 10 espécies, sendo uma endêmica; no Peru são nove espécies, na Venezuela oito e no Brasil, Equador e Panamá, sete espécies cada um (Secco 1997).

Em uma revisão da tribo Alchorneae para a região neotropical (Secco 1997) foram detectadas duas novidades taxonômicas em Alchornea, que a seguir serão descritas e discutidas.

\section{Resultados e Discussão}

1. Alchornea anamariae R. Secco, sp. nov. Tipo - BOLÍVIA: DEPTO. LA PAZ: Prov. Nor Yungas, $4 \mathrm{~km} \mathrm{NE}$ above Incahuara, 13,5 km above San

1. Parte de tese de doutorado sob orientação de A. M. Giulietti, Instituto de Biociências, Universidade de São Paulo.

2. Museu Paraense Emilio Goeldi, Depto. de Botânica, Caixa Postal 399, 66040-170 Belém, PA, Brasil.
Pedro, 1530 - 1560m alt., I - 1984 (bot., fl. estam.), Gentry \& Solomon 44439 (holótipo, MO; isótipo, F).

Figuras 1-9.

Frutices, arbusculae vel lianae. Ramuli tomentosi vel pubescentes. Folia penninervia, petiolis striatis, pubescentibus vel glabris; limbi lanceolati vel ellipticolanceolati, apice chartacei vel subcoriacei, acuminate, basi modice rotundati vel cordati, indumentis stellatis praecipue in superficie abaxiale. Inflorescentiae cauliflorae, illae staminales in paniculis; illae pistillatae in racemis dispositae. Flores staminales pedicellati, calyce gamosepalo, 2-(3-)lobato, lobis ovalibus vel lanceolatis; stamina 8 , filamentis subulatis. Flores pistillati subsessiles, calyce gamosepalo, 4-lobato, lobis sagittatis, pubescentibus; ovarium subglobosum, tomentosum, 2-loculare; styli 2, filiformes. Fructus elliptici, purpurascentes; mericarpia 2, rarius 1; semina (1)2, globosa, rubra, leviter rugosa, ecarunculata.

Arbustos, arvoretas ou lianas, ca. $3 \mathrm{~m}$ alt. Ramos tomentosos ou pubescentes. Folhas peninérveas, às vezes irregularmente trinérveas na base, pecíolos 2,5$12 \mathrm{~cm}$ compr., estriados, levemente canaliculados ou não, pubescentes a glabros; limbos 9-26 cm compr., 4,5-10,5 cm larg., lanceolados a elíptico-lanceolados, mais raro elíptico-ovais, cartáceos a subcoriáceos, ápices acuminados, bases levemente arredondadas a cordadas, glândulas 2-3, pouco perceptíveis, margens onduladas a crenado-glandulosas; face adaxial com nervura principal levemente proeminente e as demais, impressas, às vezes com convexidades, indumento de tricomas estrelados concentrado nas nervuras; face abaxial com nervuras proeminentes (às vezes, acen- 
tuadamente), algumas vezes o limbo côncavo (planta feminina) com indumento de tricomas estrelados, velutino, macio ao tato, às vezes o indumento apenas esparsamente distribuído na lâmina e, então, áspero ao tato; domácias pilosas presentes nas nervuras. Plantas masculinas com inflorescências em panículas ramosas, caulifloras, $15-50 \mathrm{~cm}$ compr., flores dispostas em glomérulos, raques pubescentes. Flores estaminadas com pedicelos $0,5-1 \mathrm{~mm}$ compr., bractéolas escamiformes, $0,5 \mathrm{~mm}$ compr., pubescentes e ciliadas; cálice com lobos 2(3), ovais ou lanceolados, pubescentes, 1,5 mm compr.; estames 8,1-1,5 mm compr., filetes subulados. Plantas femininas com inflorescências em racemos (vista apenas com frutos), caulifloras, 6-12 cm compr., as raques pubescentes. Flores pistiladas (vista apenas uma), subsésseis, pedicelos ca. 0,5 mm compr., bractéolas sagitadas, pubescentes; cálice gamossépalo, lobos 4 , sagitados, pubescentes, ca. 1,5 mm compr.; ovário subgloboso, tomentoso, ca. $2 \mathrm{~mm}$ compr., 1,5 mm larg., 2-locular, estiletes 2, filiformes, quase livres na base, $10-20 \mathrm{~mm}$ compr., esparso-pubescentes na face externa, levemente rugosos e glabros na interna. Fruto elíptico, arroxeado, mericarpos 2 ou 1 por aborto da semente, $0,5-1 \mathrm{~cm}$ diam., rugoso no material seco, pubescente; sementes (1)2, globosas, 0,6 cm compr., 0,5-0,6 cm larg., vermelhas, levemente rugosas.

Distribuição: Alchornea anamariae é endêmica das florestas úmidas da província Nor Yungas, Bolívia. Foi coletada entre 1500 - $1560 \mathrm{~m}$ de altitude, com flores estaminadas, pistiladas e frutos em janeiro.

Parátipo: BOLÍVIA: LA PAZ: Nor Yungas, on road through Incahuara-Mejillones and along trail to 12 de Outubre, 15-16-I-1983 (fl., fr.), Solomon 9277 (F, MO).

Alchornea anamariae mostra uma certa afinidade com A. bogotensis Pax \& K. Hoffm., especialmente por apresentar algumas plantas pistiladas com folhas côncavas. Entretanto, algumas características são muito típicas e diferenciais em relação àquela espécie, tais como: o hábito, que pode ser lianescente, folhas peninérveas, elípticas ou elíptico-lanceoladas, até $26 \mathrm{~cm}$ de comprimento, inflorescência cauliflora, sendo que a estaminada pode atingir até $50 \mathrm{~cm}$ de comprimento, as flores estaminadas apresentam os lobos do cálice pubescentes, ovário tomentoso com estiletes em geral longos, filiformes, até ca. $20 \mathrm{~mm}$. Alchornea bogotensis é uma espécie arbustiva ou arbórea, com folhas palmatinérveas, inflorescências axilares e terminais, a estaminada com $6-10 \mathrm{~cm}$ de comprimento, as flores estaminadas com os lobos do cálice glabros e o ovário pubescente a glabro, com estiletes curtos (4-8 mm compr.).

As duas espécies são alopátricas. Alchornea bogotensis ocorre no Equador, na Colômbia e Venezuela.

O nome da espécie é uma homenagem à Dra. Ana Maria Giulietti, da Universidade de São Paulo, pelo seu dedicado trabalho em prol da formação de recursos humanos para a taxonomia vegetal.

2. Alchornea pubescens (Britton) R. Secco, comb. nov. Conceveiba pubescens Britton (pro parte) in Rusby, Bull. Torrey bot. Club 28:306. 1911.

Tipo - BOLÍVIA: Near Yungas, 1855 (fl.), Bang 2655 (lectótipo, F; isolectótipo, US, aqui designados).

Syn. nov.: Alchornea iricurana f. pubescens (Britton) Pax \& K. Hoffm. (pro parte) in Engler, Das Pflanzereich 4.147.7:233. 1914.

Figuras 10-22.

Árvores dióicas, ocasionalmente monóicas, 8-12 $\mathrm{m}$ alt. Ramos com delicado indumento de tricomas estrelados. Folhas palmatinérveas, pecíolos $1-8 \mathrm{~cm}$ compr., canaliculados, com denso indumento de tricomas estrelados; limbos 9-18 cm compr., 6,5-12 cm larg., ovais, oval-elípticos a elípticos, coriáceos, ápice agudo a obtuso, base cordado-auriculada, glândulas 2-8, achatadas, margens serrilhado-glandulosas; face adaxial com nervuras impressas, delicado indumento de tricomas estrelados, mais concentrado nas nervuras; face abaxial com nervuras proeminentes, denso indumento de tricomas estrelados, domácias presentes na axila das nervuras secundárias, glândulas esparsamente distribuídas no tecido. Plantas masculinas com inflorescências em panículas, terminais, $35-40 \mathrm{~cm}$ compr., robustas, as flores dispostas em densos glomérulos, raques com denso indumento de tricomas estrelado-dendríticos. Flores estaminadas (observadas apenas em pré-antese) com pedicelos 1-2 mm, glabros, bractéolas sagitadas, tricomas estrelados, botões subglobosos a globosos, 2-3 mm compr., 2,5-4 mm larg., glabros; lobos do cálice 2, orbiculares, côncavos, glabros, 3-4 mm compr., 3-4 mm larg., estames 2,5-3 mm compr., filetes inseridos na parte central do dorso das anteras ( $2 \mathrm{~mm}$ compr.). Plantas femininas com inflorescências em racemos, terminais, $20-30 \mathrm{~cm}$ compr., flores isoladas ou aos pares, raques com delicado indumento de tricomas estrelado-dendríticos. Flores pistiladas com pedicelos 


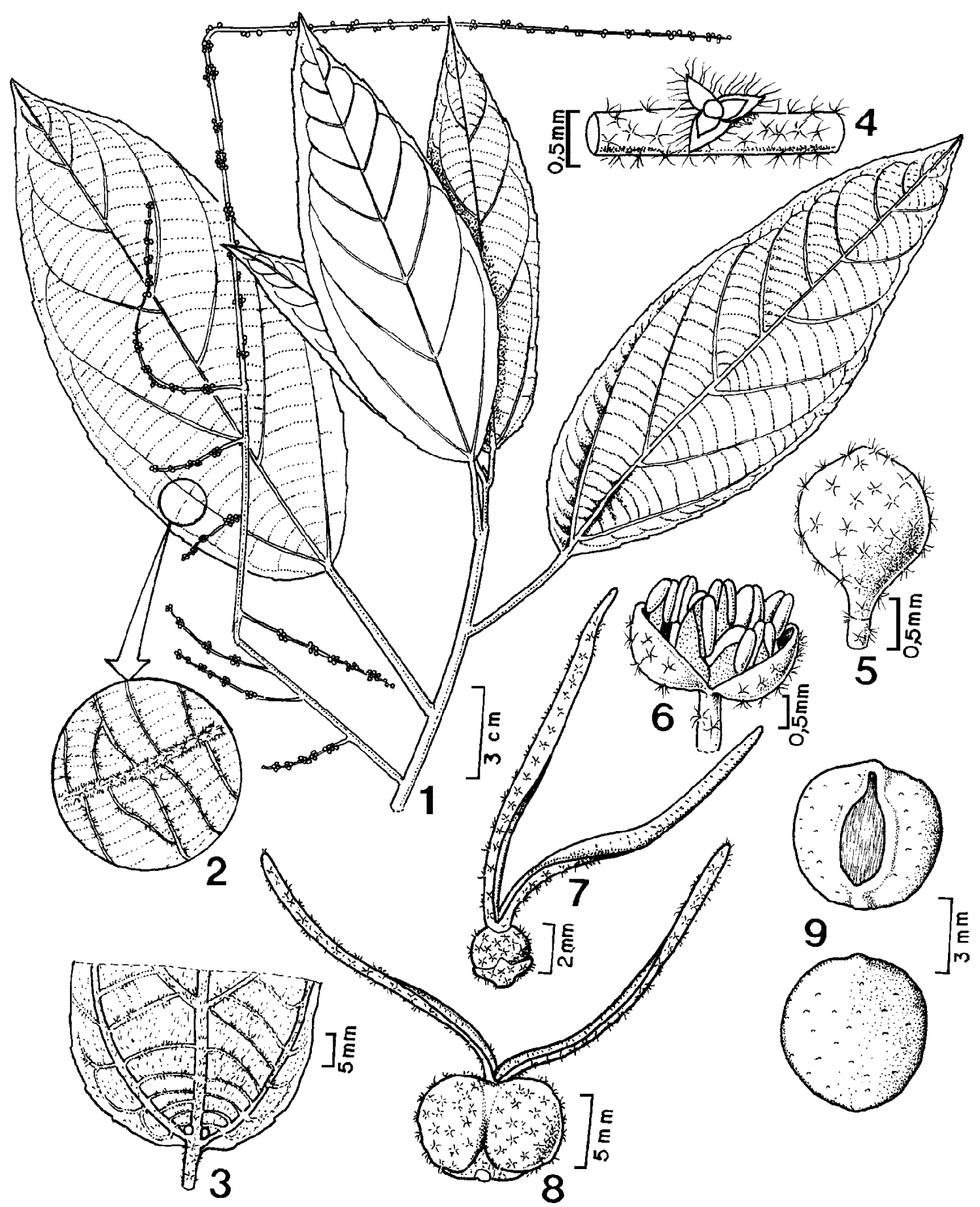

Figuras 1-9. Alchornea anamariae R. Secco. 1. Ramo com inflorescência estaminada. 2. Detalhe da nervura com tricomas estrelados. 3. Folha mostrando a face abaxial com glândulas na base. 4. Trecho da inflorescência mostrando as bractéolas da flor estaminada. 5 . Botão da flor estaminada. 6. Flor estaminada mostrando o androceu. 7. Flor pistilada. 8. Fruto maduro. 9. Sementes: faces ventral e dorsal. 1, 2, 5 Gentry 44439. 3, 7-9 Solomon 9227. 4, 6 Gentry 44624. 


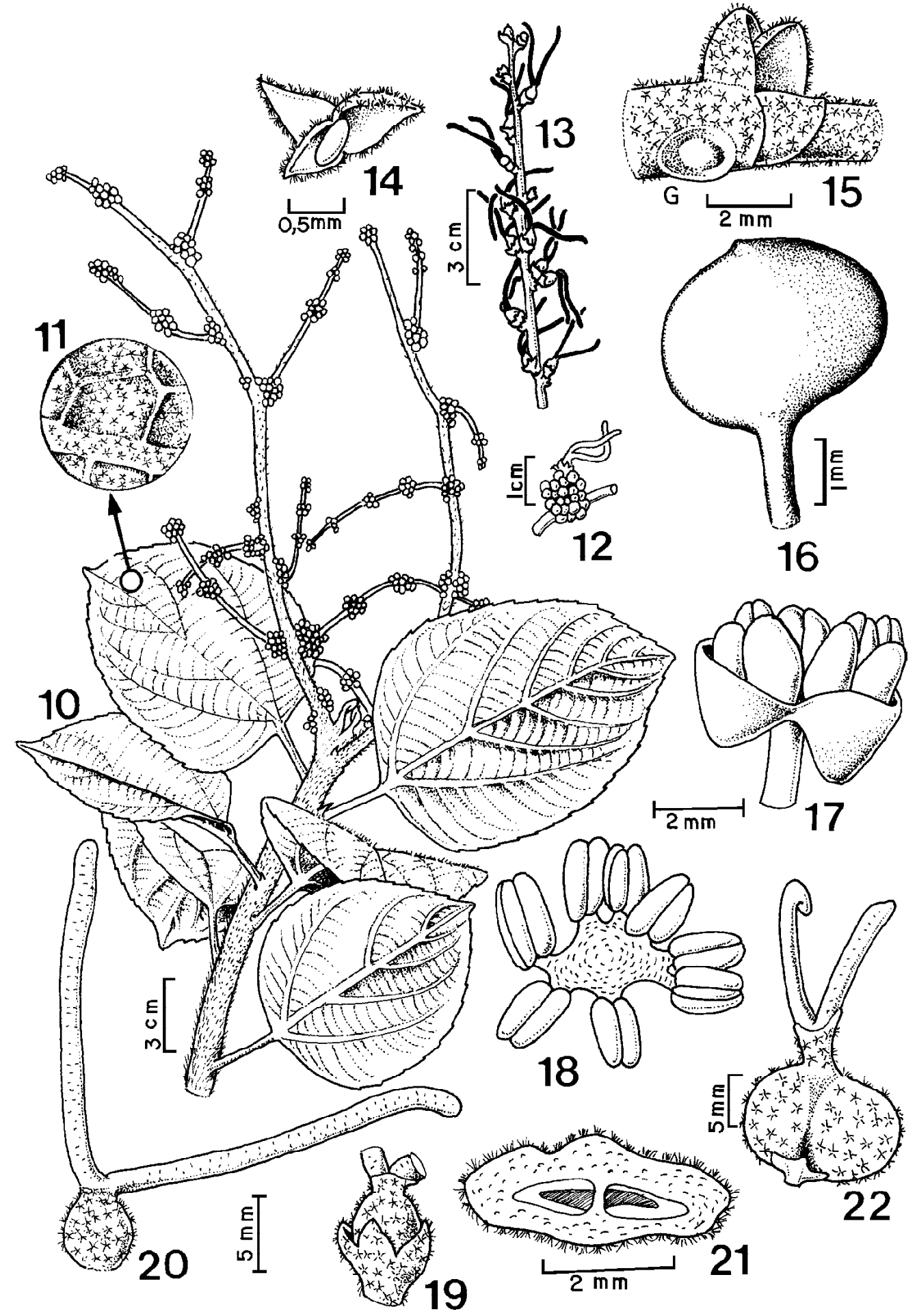

Figuras 10-22. Alchornea pubescens. 10. Ramo com inflorescência estaminada. 11. Detalhes das nervuras da folha com tricomas estrelados. 12. Glomérulo de botões estaminados com 1 flor pistilada. 13. Inflorescência pistilada. 14. Bractéolas da flor estaminada. 15. Trecho da inflorescência pistilada mostrando as bractéolas da flor e uma glândula (G). 16. Botão da flor estaminada. 17. Flor estaminada. 18. Androceu. 19. Flor pistilada sem os estiletes. 20. Flor pistilada mostrando estiletes rugosos e ovário. 21. Corte do ovário. 22. Fruto maduro. 10-12, 14, 16-18 Solomon 16664. 13, 15, 19-21 Solomon \& Kruijt 11536. 22. Beck \& Vasquez 4001. 
1-2 mm compr., bractéolas sagitadas, tricomas estrelados 2-3 mm compr.; cálice gamossépalo, lobos 4, sagitados, 3-4 mm compr., indumento de tricomas estrelados externamente; ovário subgloboso a globoso, 3-3,5 mm compr., 3-3,5 mm larg., 2-locular, denso-tomentoso, glândulas 2, laterais, estiletes 2, filiformes, concrescidos na base, 1,5-3 cm compr., pilosos na face externa, levemente rugosos a lisos e glabros na face interna. Fruto imaturo elíptico, mericarpos 2 ou 1 por aborto da semente, 1,2-1,5 $\mathrm{cm}$ diâm., rugoso no material seco, pubescente; sementes depauperadas, não analisadas.

Distribuição: Alchornea pubescens é conhecida apenas de matas da Bolívia, em altitudes entre 2000 e $2800 \mathrm{~m}$. Foi coletada com flores em fevereiro, maio e junho e com frutos em junho.

Espécimes adicionais examinados - BOLÍVIA: DEPTO. LA PAZ: Prov. Murillo, valle del rio Zongo, 2800 m, 1-V-1987 (fl.), Solomon 16664 (CTES, F, MO); idem: PROV. NOR YUNGAS, 3 km SE (below) Chuspidata on road to Chulumani, 12-II-1984 (fl., fr.), Solomon \& Kruijt 11536 (F, MO); DEPTO. COCHABAMBA: PROV. CHAPARE, carretera al Chapare, $2500 \mathrm{~m}$, 5-VI-1980 (fr.), Beck \& Vasquez 4001 (LPB); DEPTO. PASCO: Oxapampa-Cerro Pasco road, 2000-2500 m, 3-II-1983 (fl., fr.), Gentry et al. 39947 (F, MO).

Ao descrever Conceveiba pubescens, Britton (in Rusby 1901) citou as coleções Bang 2655 (flores estaminadas) e Bang 2375 (flores pistiladas) como síntipos. Deixou, entretanto, dúvida sobre a identidade de Bang 2375 (pistillate plant, if Mr. Bang's no 2375 is the same). Analisando-se estes materiais escolheu-se Bang 2655 como lectótipo de Conceveiba pubescens (basiônimo de A. pubescens), pois Bang 2375 é um espécime pistilado de $A$. glandulosa subsp. glandulosa.

Alchornea pubescens é separada facilmente das demais espécies do gênero, especialmente por apresentar os botões florais estaminados muito grandes, podendo atingir até $3 \mathrm{~mm}$ compr. $\mathrm{x} 4 \mathrm{~mm}$ larg., reunidos em densos glomérulos, uma característica incomum para o gênero. A espécie mais próxima de $A$. pubescens é A. sidifolia, espécie típica do sudeste e sul do Brasil. As duas espécies são alopátricas (Fig. 23) e diferenciam-se pelos caracteres listados na tabela 1 .

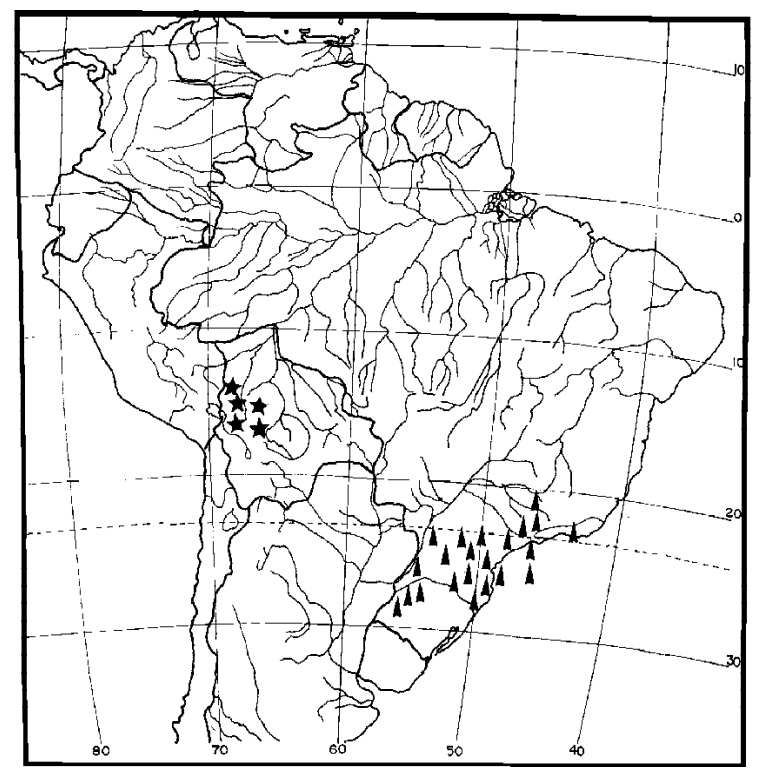

Figura 23. Distribuição geográfica de Alchornea sidifolia (\) e Alchornea pubescens $(\star)$.

Tabela 1. Caracteres que diferenciam Alchornea pubescens de A. sidifolia.

\begin{tabular}{ll}
\hline Alchornea pubescens (Britton) R. Secco & A. sidifolia Muell. Arg. \\
\hline Ramos com tricomas estrelados, não velutinos. & Ramos densamente velutinos. \\
Folhas coriáceas. & Folhas cartáceas. \\
Base foliar auriculada. & Base foliar não auriculada. \\
Inflorescências estaminadas em panículas robustas. & Inflorescências estaminadas em panículas delicadas. \\
Botões até 3,0 x 4,0 mm, glabros. & Botões até $1,5 \times 1,5 \mathrm{~mm}$, pubescentes ou apenas com tricomas apicais. \\
Lobos da flor pistilada sagitados, concrescidos na base, & Lobos da flor pistilada estreito-lanceolados, quase livres, \\
não cobrindo o ovário. & cobrindo o ovário. \\
Ovário tomentoso, $3-3,5 \mathrm{~mm}$ compr. & Ovário hirsuto, $1,5-2 \mathrm{~mm}$ compr. \\
Estiletes longos, $1,5-3 \mathrm{~cm}$ compr. & Estiletes curtos, até $1 \mathrm{~cm}$ compr. \\
Frutos de pelo menos $1,2-1,5 \mathrm{~cm}$ diâm. & Frutos até $1 \mathrm{~cm}$ diâm. \\
\hline
\end{tabular}


Agradecimentos - Ao CNPq, pelas bolsas de doutorado (processo no 140.450.91/2) e de pesquisa (processo no 301.252/86-6) concedidas; à Dra. Ana Maria Giulietti, da Universidade de São Paulo e Universidade Estadual de Feira de Santana, pela orientação a esta pesquisa; ao Dr. William Rodrigues, da Universidade Federal do Paraná, pela confecção das diagnoses latinas; ao Elielson Rocha, bolsista do PCI-CNPq, pelos desenhos dos hábitos das plantas e sombreamento das partes reprodutivas; ao Celso Moraes, pela digitação e formatação do texto.

\section{Referências bibliográficas}

PAX, F. \& HOFFMANN, K. 1914. Euphorbiaceae-AcalypheaeMercurialinae. In Das Pflanzenreich (A. Engler, ed.) 4. 147.7:7-259.

RUSBY, H.H. 1901. An enumeration of the plants collected by Dr. H. H. Rusby in South America, 1885 - 1886, XXXI. Bull. Torrey bot. Club 28:301-309.

SECCO, R.S. 1997. Revisão taxonômica das espécies neotropicais da tribo Alchorneae (Hurusawa) Hutchinson (Euphorbiaceae) Tese de doutorado, Universidade de São Paulo, São Paulo.

WEBSTER, G.L. 1994. Synopsis of the genera and suprageneric taxa of Euphorbiaceae. Ann. Mo. bot. Gdn 81:33-144. 